Jurnal Sulolipu : Media Komunikasi Sivitas Akademika dan Masyarakat

Vol. 19 No.12019

e-issn : 2622-6960, p-issn : 0854-624X

\title{
STUDI KUALITAS UDARA AMBIEN SULFUR DIOKSIDA (SO2) DI TPA TAMANGAPA KOTA MAKASSAR Sachnaz Chalid ${ }^{1}$ Rasman $^{2}$ \\ 1,2 Jurusan Kesehatan Lingkungan Poltekkes Kemenkes Makassar ychalid@gmail.com , rasmanjbr@gmail.com
}

\begin{abstract}
In general, the final processing of waste carried out at landfills (TPAS) is mostly carried out by open dumping, the absence of overburden will cause air pollution to not be damped. Gas production arising from the degradation of waste material will cause unpleasant odors and also added with flying dust. Pollutant gas from TPAS will produce, among others, sulfur dioxide gas (SO2). This study aims to determine the ambient air quality of Sulfur Dioxide (SO2) in the TPA Tamangapa Landfill, To find out the level of ambient sulfur dioxide (SO2) air pollution, and to determine the distribution of SO2 in the TPA Tamangapa Makassar City. This type of research is a descriptive observation with cross-sectional study design. The results obtained during the examination of Sulfur dioxide gas (SO2) value obtained at the point I is 0 ppm, point II is $0.1 \mathrm{ppm}$, point III is $0.1 \mathrm{ppm}$, point IV is $0.1 \mathrm{ppm}$, point $V$ is $0.1 \mathrm{ppm}$, and the point is VI of $0.2 \mathrm{ppm}$. With an average measurement of Sulfur Dioxide (SO2) concentration in Tamangapa Landfill at $0.1 \mathrm{ppm}$ (260 $\mu \mathrm{g} / \mathrm{Nm} 3$ ), temperature $34^{\circ} \mathrm{C}$, humidity $28 \%$, and wind speed $5.8 \mathrm{~m} / \mathrm{s}$. The conclusion is that the ambient air quality of Sulfur dioxide (SO2) in the Tamangapa Landfill is categorized as fulfilling the requirements according to Government Regulation of the Republic of Indonesia Number 41 of 1999 concerning Air Pollution Control.
\end{abstract}

Keywords: Ambient Air Quality, Sulfur Dioxide (SO2), Tamangapa Landfill

\section{ABSTRAK}

Pada umumnya pemrosesan akhir sampah yang dilaksanakan di tempat pembuangan akhir sampah (TPAS) sebagian besar dilaksanakan dengan open dumping, ketiadaan tanah penutup akan menyebabkan polusi udara tidak teredam. Produksi gas yang timbul dari degradasi materi sampah akan menyebabkan bau yang tidak sedap debu yang beterbangan. Gas polutan yang berasal dari TPAS akan menghasilkan antara lain gas sulfur dioksida (SO2). Penelitian in bertujuan untuk mengetahui kualitas udara ambien Sulfur Dioksida (SO2) di TPA Tamangapa, Untuk mengetahui kadar cemaran udara ambien sulfur dioksida (SO2), serta Untuk mengetahui sebaran SO2 di TPA Tamangapa Kota Makassar. Jenis penelitian ini adalah observasi yang bersifat deskriptif dengan rancangan penelitian cross-sectional. Hasil yang didapat pada saat melakukan pemeriksaan gas Sulfur dioksida (SO2) nilai yang di dapat pada titik I sebesar 0 ppm, titik II sebesar $0.1 \mathrm{ppm}$, titik III sebesar $0.1 \mathrm{ppm}$, titik IV sebesar $0.1 \mathrm{ppm}$, titk V sebesar $0.1 \mathrm{ppm}$, dan titik VI sebesar $0.2 \mathrm{ppm}$. Dengan rata-rata pengukuran konsentrasi Sulfur dioksida (SO2) di TPA Tamangapa sebesar $0.1 \mathrm{ppm}\left(260 \mu \mathrm{g} / \mathrm{Nm}^{3}\right)$, suhu $34^{\circ} \mathrm{C}$, kelembaban 28\%, dan kecepatan angin $5.8 \mathrm{~m} / \mathrm{s}$. Kesimpulannya yaitu kualitas udara ambien Sulfur dioksida (SO2) di TPA Tamangapa dikategorikan memenuhi syarat menurut Peraturan Pemerintah Republik Indonesia Nomor 41 Tahun 1999 Tentang Pengendalian Pencemaran Udara.

Kata kunci: Kualitas Udara Ambien, Sulfur Dioksida (SO2), TPA Tamangapa

\section{PENDAHULUAN}

Udara merupakan zat yang paling penting setelah air dalam memberikan kehidupan dipermukaan bumi ini. Selain memberikan oksigen untuk keperluan bernafas, udara juga dapat menjadi media penyebaran penyakit pada manusia. Pada suatu keadaan ketika pencemaran yang terjadi melebihi kemampuan alam untuk membersihkan dirinya sendiri, pencemaran itu akan membahayakan kesehatan manusia dan memberikan dampak yang luas terhadap ekosistem yang ada di lingkungan kita ini.

Belerang dioksida atau SO2, gas jernih tak berwarna ini merupakan bagian dari pencemar udara. Jumlah S02 karena oksidasi $\mathrm{H} 2 \mathrm{~S}$ adalah $80 \%$. Sisa $20 \%$ SO2 lagi adalah hasil ulah manusia yakni akibat bahan bakar yang mengandung belerang dan pelelehan logam non-ferro, kilang minyak, dan letusan gunung. Gas ini baunya menyengat dan amat membahayakan manusia. Dari $20 \%$ ini yang $16 \%$ adalah akibat pembakaran zat-zat yang mengandung belerang seperti minyak bumi dan batu bara. Inilah yang membahayakan kesehatan di kota-kota, karena penyebaran SO2 di muka bumi tidak merata.( Sastrawijaya A. Tresna, 2009)

Pada umumnya pemerosesan akhir sampah yang dilaksanakan di tempat pembuangan akhir sampah (TPAS) sebagian besar dilaksanakan dengan open dumping, yang mengakibatkan permasalahan lingkungan, seperti pencemaran udara akibat gas, bau, dan debu. Ketiadaan tanah penutup akan menyebabkan polusi udara tidak teredam. Produksi gas yang timbul dari degradasi materi sampah akan menyebabkan bau yang tidak 
Jurnal Sulolipu : Media Komunikasi Sivitas Akademika dan Masyarakat

Vol. 19 No.12019

e-issn : 2622-6960, p-issn : 0854-624X

sedap dan juga ditambah dengan debu yang beterbangan. Gas polutan yang berasal dari TPAS akan menghasilkan antara lain gas sulfur dioksida (SO2), gas amonia (NH3), dan gas hidrogen sulfida $(\mathrm{H} 2 \mathrm{~S})$ yang bersifat racun bagi tubuh. (Siregar, 2011).

Bukan hanya pada proses pembusukan sampah gas $\mathrm{H} 2 \mathrm{~S}$ dapat terbentuk, akan tetapi di TPA dapat kita temukan hewan ternak (sapi) yang melangsungkan hidup di tempat ini yang kemudian kotoran yang dihasilkan oleh hewan tersebut akan menghasilkan gas H2S dan terdekomposisi menjadi $\mathrm{SO} 2$ dan proses ini merupakan sumber alamiah terbentuknya gas sulfur dioksida. Hasil pengukuran gas $\mathrm{SO} 2$ yang dihasilkan oleh proses dekomposisi sampah di TPA Tamangapa Kota Makassar sebesar 975,60 $\mu \mathrm{g} \mathrm{/} \mathrm{Nm}^{3}$ dikatakan tidak memenuhi syarat (di atas baku mutu udara ambien). (Fakhrunnisa, 2016)

\section{BAHAN DAN METODE}

\section{Lokasi Penelitian:}

Waktu penelitian dimulai dengan pengajuan judul penelitian, survey awal, penelusuran daftar pustaka, persiapan proposal, konsultasi dengan pembimbing, pelaksanaan penelitian, pengumpulan data dan pengolahan data sampai dengan penyusunan laporan akhir direncanakan berlangsung selama 6 bulan.

Penelitian ini di lakukan di lokasi Tempat Pembuangan Akhir (TPA) Tamangapa, di Kecamatan Manggala, Kota Makassar.

\section{Desain dan Variabel Penelitian}

Pemeriksaan kadar sulfur dioksida di TPA Tamangapa dilakukan dengan menggunakan alat OdaLog 7000 series dan dibagi 6 titik pengukuran dengan jarak yaitu $\pm 100 \mathrm{~m}$. Variabel bebas adalah variabel yang mempengaruhi variabel terikat yaitu kualitas udara ambien di TPA Tamangapa dan Variabel terikat adalah variabel yang dipengaruhi oleh variabel bebas yaitu Kadar cemaran Sulfur dioksida (SO2) dan sebaran Sulfur dioksida (SO2). Variabe pengganggu adalah variabel yang mempengaruhi variabel terikat tetapi tidak diteliti yaitu suhu, kelembapan, kecepatan angin, dan musim.

\section{Populasi dan Sampel}

Populasi dalam penelitian ini adalah lokasi Tempat Pembuangan Akhir (TPA) Tamangapa dan pertimbangan pengambilan sampel yang tersebar diberikan jarak $\pm 100 \mathrm{~m}$ dari setiap titik yang telah ditentukan dengan jumlah sampel sebanyak 6 titik, yang dimulai dari jembatan timbang sampah.

\section{Pengumpulan data}

Data primer adalah data yang diperoleh berdasarkan hasil pemeriksaan langsung di TPA Tamangapa

Data sekunder adalah data yang diperoleh dari berbagai referensi baik buku, jurnal, artikel- artikel maupun literatur yang lain yang dianggap dapat mendukung teori yang ada, serta dianggap memiliki keterkaitan dengan penelitian ini.

\section{Analisa Data}

Pengolahan data yang digunakan pada penelitian ini adalah dengan cara komputerisasi dengan menggunakan program Microsoft Word, dan Microsoft Excel. Penyajian data yang digunakan dalam penelitian ini adalah dalam bentuk tabel dan grafik.

\section{HASIL}

Berdasarkan hasil penelitian pemeriksaan kualitas udara ambien Sulfur dioksida (SO2) dengan menggunakan alat OdaLog 7000 series di Tempat Pembuangan Sampah Akhir (TPA) Tamangapa Kec. Manggala, Kel. Antang, Kota Makassar dengan memakai standar menurut Peraturan Pemerintah Republik Indonesia Nomor 41 Tahun 1999 Tentang Pengendalian Pencemaran Udara, hasilnya dapat diuraikan sebagai berikut: 
Jurnal Sulolipu : Media Komunikasi Sivitas Akademika dan Masyarakat

Vol. 19 No.12019

e-issn : 2622-6960, p-issn : 0854-624X

Tabel 1

Hasil Pemeriksaan Kualitas Udara ambien Sulfur Dioksida (SO2) TPA

Tamangapa Kota Makassar

\begin{tabular}{|c|c|c|c|c|}
\hline \multirow[t]{2}{*}{ No } & \multirow{2}{*}{$\begin{array}{c}\text { Titik } \\
\text { pengukuran }\end{array}$} & \multicolumn{2}{|c|}{$\begin{array}{l}\text { Konsentrasi } \\
\text { SO2 }\end{array}$} & \multirow[t]{2}{*}{ Keterangan } \\
\hline & & ppm & $\begin{array}{l}\mu \mathrm{g} / \\
\mathrm{Nm} 3\end{array}$ & \\
\hline 1 & 1 & 0 & 0 & $\begin{array}{c}\text { Memenuhi } \\
\text { syarat }\end{array}$ \\
\hline 2 & II & 0.1 & 260 & $\begin{array}{c}\text { Memenuhi } \\
\text { syarat }\end{array}$ \\
\hline 3 & III & 0.1 & 260 & $\begin{array}{c}\text { Memenuhi } \\
\text { syarat }\end{array}$ \\
\hline 4 & IV & 0.1 & 260 & $\begin{array}{l}\text { Memenuhi } \\
\text { syarat }\end{array}$ \\
\hline 5 & V & 0.1 & 260 & $\begin{array}{l}\text { Memenuhi } \\
\text { syarat }\end{array}$ \\
\hline \multirow[t]{2}{*}{6} & VI & 0.2 & 520 & $\begin{array}{c}\text { Memenuhi } \\
\text { syarat }\end{array}$ \\
\hline & Rata-rata & 0.1 & 260 & $\begin{array}{c}\text { Memenuhi } \\
\text { syarat }\end{array}$ \\
\hline
\end{tabular}

Sumber: data primer, 2018

Berdasarkan tabel 4.1 menunjukan bahwa dari enam titik pengambilan sampel maka diperoleh hasil tertinggi yaitu, pada titik VI di daerah pembuangan sampah awal dengan konsentrasi Sulfur dioksida yaitu 0.2 ppm (520 $\mu \mathrm{g} / \mathrm{Nm}^{3}$ ) sedangkan hasil terendahdiperoleh pada titik I dengan hasil 0 ppm di jembatan timbang sampah dengan kategori memenuhi syarat.

Tabel 4.2

Hasil Pengukuran Suhu, Kelembaban Dan Kecepatan Angin di TPA Tamangapa Kota Makassar

\begin{tabular}{lllll}
\hline $\begin{array}{l}\mathbf{N} \\
\mathbf{0}\end{array}$ & $\begin{array}{l}\text { Titik } \\
\text { Pengukura } \\
\mathbf{n}\end{array}$ & $\begin{array}{l}\text { Suhu } \\
\left({ }^{\circ} \mathbf{C}\right)\end{array}$ & $\begin{array}{l}\text { Kelembaba } \\
\mathbf{n}(\%)\end{array}$ & $\begin{array}{l}\text { Kecepata } \\
\mathbf{n} \text { angin } \\
(\mathbf{m} / \mathbf{s})\end{array}$ \\
\hline $\mathbf{1}$ & I & 34 & 28 & 9.6 \\
$\mathbf{2}$ & II & 34 & 28 & 7.5 \\
$\mathbf{3}$ & III & 34 & 28 & 6.4 \\
$\mathbf{4}$ & IV & 34 & 28 & 6.0 \\
\hline $\mathbf{5}$ & V & 34 & 28 & 3.8 \\
$\mathbf{6}$ & VI & 34 & 28 & 1.5 \\
& Rata-rata & 34 & 28 & 5.8 \\
\hline
\end{tabular}

Sumber: data primer, 2018

Berdasarkan pada tabel 4.2 pada lokasi penelitian dengan enam titik pengukuran di TPA Tamangapa dapat dilihat bahwa suhu sebesar $34^{\circ} \mathrm{C}$, kelembabannya sebesar $28 \%$, dan kecepatan angin pada titik I $9.6 \mathrm{~m} / \mathrm{s}$, titik II $7.5 \mathrm{~m} / \mathrm{s}$, titik III $6.4 \mathrm{~m} / \mathrm{s}$, titik IV $6.0 \mathrm{~m} / \mathrm{s}$, titik V $3.8 \mathrm{~m} / \mathrm{s}$, dan titik VI $1.5 \mathrm{~m} / \mathrm{s}$.

\section{PEMBAHASAN}

Tempat Pembuangan Akhir (TPA) Tamangapa yang berlokasi di Kelurahan Tamangapa, Kecamatan Manggala, Kota Makassar merupakan satu-satunya TPA yang berada di kota ini. Layanan TPA Tamangapa mencakup seluruh sampah yang ada di dalam kota Makassar. Menurut data Dinas Lingkungan Hidup (DLH) Kota Makassar menyebut, sampah yang masuk ke Tempat Pembuangan Akhir (TPA) Tamangapa setiap hari rata-rata 1.200 ton. Jumlah tersebut berupa sampah organik dan rumah tangga. Selama ini pembuangan sampah selalu dititik beratkan pada TPA, sehingga beban pencemar menjadi perhatian besar.

Kegiatan pengolahan sampah di TPA Tamangapa menerapkan sistem Open Dumping, dimana sampah-sampah itu dibuang begitu saja diatas permukaan tanah secara terbuka. Metode ini merupakan pembuangan sampah yang biasa dilakukan sebagai mana ditempat yang lain. Open Dumping harus dilakukan jauh dari tempat kediaman, diluar jarak terbang lalat dan tidak terlampau dekat dengan jalan besar. Produksi gas yang timbul dari degradasi materi sampah akan menyebabkan bau yang tidak sedap dan juga ditambah dengan debu yang berterbangan. Gas polutan yang berasal dari TPA menghasilkan antara lain Sulfur Dioksida (SO2), karena sumber SO2 alamiah adalah letusan gunung berapi, pembusukan bahan organik oleh mikroba dan reduksi sulfat secara biologis.

Metode yang peneliti gunakan adalah metode purposive sampling, dimana hasil yang didapat pada saat melakukan pemeriksaan gas Sulfur dioksida (SO2) nilai yang di dapat pada titik I berada dari jembatan timbang sampah yaitu sebesar 0 ppm, titik II berada setelah diukur jarak $\pm 100 \mathrm{~m}$ dari titik lokasi pertama di jembatan timbang sampah yaitu sebesar $0.1 \mathrm{ppm}$, titik III berada di tempat pengolahan sampah setelah diukur jarak $\pm 100 \mathrm{~m}$ dari titik lokasi kedua yaitu sebesar $0.1 \mathrm{ppm}$, titik IV diambil setelah diukur jarak $\pm 100 \mathrm{~m}$ dari titik lokasi ketiga di tempat 
Jurnal Sulolipu : Media Komunikasi Sivitas Akademika dan Masyarakat

Vol. 19 No.12019

e-issn : 2622-6960, p-issn : 0854-624X

pengolahan sampah yaitu sebesar $0.1 \mathrm{ppm}$, titk $\mathrm{V}$ diambil setelah diukur jarak $\pm 100 \mathrm{~m}$ yang pengukurannya dimulai dari titiklokasi keempat yaitu sebesar $0.1 \mathrm{ppm}$, dan titik VI di ambil setelah diukur jarak $\pm 100 \mathrm{~m}$ dari titik lokasi kelima dimana sampel diukur di tempat pembuangan sampah awal yaitu sebesar 0.2 ppm.

1. Kadar Cemaran Udara Ambien Sulfur
Dioksida (SO2) Di TPA Tamangapa
Dapat diketahui bahwa konsentrasi tertinggi Sulfur dioksida (SO2) di TPA Tamangapa sebesar 0.2 ppm (520 $\mu \mathrm{g} / \mathrm{Nm}^{3}$ ) ditemukan pada titik $\mathrm{VI}$ dan yang terendah berada pada titik I sebesar 0 ppm. Menurut Peraturan Pemerintah Republik Indonesia Nomor 41 Tahun 1999 Tentang Pengendalian Pencemaran Udara, konsentrasi ini masih dikatakan memenuhi syarat dikarenakan apabila memenuhi syarat kadar Sulfur dioksida (SO2) harus kurang dari atau sama dengan $900 \mu \mathrm{g} / \mathrm{Nm}^{3}$.

Pada TPA bukan hanya pada proses pembusukan sampah gas $\mathrm{H} 2 \mathrm{~S}$ dapat terbentuk, akan tetapi di TPA dapat kita temukan hewan ternak (sapi) yang melangsungkan hidup di tempat ini yang kemudian kotoran yang dihasilkan oleh hewan tersebut akan menghasilkan gas $\mathrm{H} 2 \mathrm{~S}$ dan terdekomposisi menjadi SO2 dan proses ini merupakan sumber alamiah terbentuknya gas Sulfur dioksida.(Fakhrunnisa,2016)

Sulfur dioksida merupakan ikatan yang tidak stabil dan sangat reaktif terhadap gas yang lain. Ciri lainnya adalah tidak berwarna, bau yang tajam, sangat mengiritasi, tidak terbakar dan tidak meledak. SO2 merupakan polutan yang berbahaya bagi kesehatan terutama bagi penderita penyakit kronis sistem pernafasan dan kardiovaskuler. Penderita sangat sensitif bila kontak dengan $\mathrm{SO} 2$ meskipun dalam konsentrasi yang kecil (Sunu, 2001).

Menurut Wardhana (2004), menyatakan bahwa daya iritasi sulfur dioksida (S02) pada setiap orang ternyata tidak sama. Ada orang yang sensitif dan sudah akan mengalami iritasi apabila terkena sulfur dioksida (S02) berkonsentrasi 1-2 ppm, namun ada pula orang yang baru akan mengalami iritasi tenggorokan apabila terkena sulfur dioksida (S02) berkonsentrasi 6 ppm. Dan dalam jumlah konsentrasi 3-5 ppm saja sudah dapat dideteksi dari baunya.

\section{Sebaran Udara Ambien Sulfur Dioksida (SO2) Di TPA Tamangapa}

Secara fisik yang perlu dilakukan dan diperhatikan adalah sebaran kadar SO2 di TPA dengan rata-rata SO2 adalah $0.1 \mathrm{ppm}\left(260 \mu \mathrm{g} / \mathrm{Nm}^{3}\right)$. Sebaran Sulfur dioksida (SO2) di TPA Tamangapa dilihat dari pengaruh faktor meteorologi terhadap gas SO2 yaitu :

\section{a. Suhu}

Rata-rata suhu saat
pengukuran konsentrasi gas $\mathrm{SO}_{2} \mathrm{di}$ TPA Tamangapa sebesar $34^{\circ} \mathrm{C}$. Besar konsentrasi gas SO2 di TPA tidak dipengaruhi oleh suhu. Hal ini dapat disebabkan karena selama pengukuran, besar suhu di TPA Tamangapa masih terbilang normal.

Menurut penelitian Nurul (2017), Suhu rata-rata saat pengukuran konsentrasi gas $\mathrm{SO}_{2}$ di TPA Jatibarang sebesar $33,8^{\circ} \mathrm{C}$. konsentrasi gas $\mathrm{SO}_{2}$ di TPA tidak dipengaruhi oleh suhu. Hal ini dapat disebabkan karena selama pengukuran, besar suhu di TPA Jatibarang konstan. Pada suhu udara yang lebih rendah dari lingkungan (kondisi stabil), massa udara polutan tidak dapat naik tapi tetap berada di atmosfir dan terakumulasi. Sebaliknya bila suhu udara lebih tinggi dari pada suhu lingkungan (kondisi tidak stabil), maka massa udara polutan naik dan menyebar.

\section{b. Kelembaban}

Rata-rata kelembaban saat pengukuran konsentrasi gas $\mathrm{SO} 2$ di TPA Tamangapa sebesar 28\%. Besar konsentrasi gas SO2 di TPA dapat dipengaruhi oleh kelembaban.

Menurut penelitian Nurul (2017), Hal ini dapat disebabkan karena rendahnya kelembaban udara yang dapat menaikan konsentrasi gas SO2. Kondisi udara yang lembab akan membantu proses pengendapan bahan 
Jurnal Sulolipu : Media Komunikasi Sivitas Akademika dan Masyarakat

Vol. 19 No.12019

e-issn : 2622-6960, p-issn : 0854-624X

pencemar, sebab dengan keadaan udara yang lembab maka beberapa bahan pencemar akan berikatan dengan air yang ada didalam udaradan membentuk partikel yang berukuran lebih besar sehingga mudah mengendap ke permukaan bumi oleh gaya tarik bumi.

c. Kecepatan Angin

Berdasarkan dari hasil penelitian yang telah dilakukan kecepatan angin pada lokasi penelitian di TPA Tamangapa yang tertinggi berada pada titik pengukuran ke I dengan nilai sebesar $9.6 \mathrm{~m} / \mathrm{s}$ dengan konsentrasi Sulfur dioksida (SO2) sebesar $0 \mathrm{ppm}$, sedangkan yang terendah dari kecepatan angin berada pada titik pengukuran ke $\mathrm{VI}$ dengan nilai sebesar $1.5 \mathrm{~m} / \mathrm{s}$ dengan konsentrasi Sulfur dioksida (SO2) sebesar $0.2 \mathrm{ppm}$.

Menurut penelitian Nurul (2017), Hal tersebut dapat terjadi karena apabila kecepatan angin melemah maka polutan akan menumpuk ditempat dan dapat mencemari udara tempat pemukiman yang terdapat di sekitar lokasi pencemaran tersebut. Sedangkan, ketika angin bergerak dengan kecepatan yang tinggi maka pencemar akan mengalami penurunan melalui dispersi.

d. Musim

Berdasarkan dari pelaksanaan penelitian di TPA Tamangapa saat melakukan pemeriksaan kadar Sulfur dioksida (SO2) dalam masa peralihan, dikatakan demikian karena terjadi perubahan antara musim hujan dan musim kemarau yang biasa terjadi pada bulan april- oktober di daerah iklim muson. Sehari sebelum pengukuran terjadi hujan sehingga hasil pengukuran kadar $\mathrm{SO}_{2}$ udara ambient masih dalam kategori memenuhi syarat. Hal ini dapat disebabkan kondisi hujan pada malam sebelum pengukuran merupakan proses pencucian udara oleh air hujan.

\section{PENUTUP}

\section{Kesimpulan}

a. Kualitas udara ambien Sulfur dioksida (SO2) Di TPA Tamangapa terendah pada titik I tidak ada kadar $\mathrm{SO} 2$ sedangkan yang tertinggi pada titik $\mathrm{VI}$ sebesar $0.2 \mathrm{ppm}$

b. Sebaran Sulfur dioksida (SO2) di TPA Tamangapa adalah $0.1 \mathrm{ppm}(260 \mu \mathrm{g} /$ $\mathrm{Nm}^{3}$ ), suhu $34^{\circ} \mathrm{C}$, kelembaban $28 \%$, dan kecepatan angin $5.8 \mathrm{~m} / \mathrm{s}$.

\section{Saran}

a. Untuk pemerintah Dinas Lingkungan Hidup kota Makassar hendaknya melakukan pengukuran kualitas secara rutin agar diketahui konsentrasi polutan udara di TPA Tamangapa Kota Makassar.

b. Untuk masyarakat yang tinggal di sekitar TPA Tamangapa agar memakai ventilasi yang sesuai.

\section{DAFTAR PUSTAKA}

Achmad Zubair dan Haeruddin. 2012. Studi Potensi Daur Ulang Sampah Di TPA Tamangapa Kota Makassar. Makassar: Jurusan Teknik Sipil Unhas (online)

(http://download. portalgaruda.org/article.php?article=94529\&val=2170, 18 Januari 2017 )

EPA. 2016. Sulfur Dioxide Basics. (jurnal, online) (https://www.epa.gov/so2-pollution/sulfur-dioxidebasics, diakses pada 23 Desember 2017)Fakhrunnisa Amri. 2016. Identifikasi Gas Sulfur Dioksida (SO2) Dari Berbagai Sumber Di Kota Makassar Sulawesi Selatan. Makassar: Program Diploma III Jurusan Kesehatan Lingkungan. Kti Tidak Diterbitkan

Ma'ruf Al Anshari, Mohammad. 2017. Studi Reduksi Sulfur Dioksida Udara Ambien Oleh Vegetasi untuk Wilayah Permukiman dan Ruang Terbuka Hijau di Kota Surabaya. Surabaya: Fakultas Teknik Sipil dan Perencanaan Institut Teknologi Sepuluh Nopember Surabaya 
Jurnal Sulolipu : Media Komunikasi Sivitas Akademika dan Masyarakat

Vol. 19 No.12019

e-issn : 2622-6960, p-issn : 0854-624X

(online) (http://repository.its.ac.id/43521/1/3313100025_Undergraduate_Theses.pdf, diakses pada 14 Desember 2017)

Mukono, H.J. 2008. Pencemaran Udara dan Pengaruhnya Terhadap Gangguan Saluran Pernapasan. Surabaya: Universitas Airlangga, cetakan ketiga

Nurul Chaerunnisa. 2016. Gambaran Pengelolaan Pelayanan Kesehatan Berdasarkan Fungsi Manajemen Pada Program Pengendalian Penyakit Menular (P2m) Di Puskesmas Tamangapa Makassar Tahun 2016. Skripsi Jurusan Kesehatan Masyarakat, Universitas Islam Negeri Alauddin, Makassar. (online) (http://repositori.uinalauddin.ac.id/2159/1/PDF\%20CHaerunnisa.PDF, diakses pada 23 Desember 2017)

Nurul Annisa. 2017. Pengukuran dan Pemetaan Konsentrasi gas SO2 dan NO2 di Tempat Pemrosesan Akhir Sampah (TPA) Jatibarang. Jurnal Teknik Lingkungan, Universitas Diponegoro, Semarang.(online) (http://eprints.undip.ac.id/56467/1/NURUL_ANNISA_21080113120046_JURNAL.pdf) , diakses pada 3 Januari 2018)

Republik Indonesia. 1999. Peraturan pemerintah no. 41 tahun 1999 tentang pengendalian pencemaran udara

Redaktur. 2018. Petugas Kebersihan memahami Kondisi Pemerintahan Kota makassar Saat ini.

Makassar (online) (http://www.makassarkota.go.id/berita-2603-petugas-kebersihan memahamikondisi- pemerintahan-kota-makassar-saat-ini.html, diakses pada 24 Juli 2018)

Rompas,Rizald Max. 1998. Kimia Lingkungan. Bandung: Tarsito Rukaesih A. 2004. Kimia Lingkungan. Jakarta: Universitas Negeri Jakarta Sarudji, D. 2010. Kesehatan Lingkungan. Bandung: Karya Putra Darwati

Sastrawijaya A. Tresna,. 2009. Pencemaran Lingkungan. Jakarta: Rineka Cipta

Siregar, F.R. 2011. Analisis Kualitas Udara dan Keluhan Kesehatan yang Berkaitan dengan Saluran Pernapasan Pada Pemulung di Tempat Pembuangan Akhir Sampah (TPA) Namo Bintang Kecamatan Pancur Batu Kabupaten Deli Serdang di Kota Medan. Skripsi Fakultas

Kesehatan Masyarakat, Universitas Sumatera Utara, Medan. (online) (http://repository.usu.ac.id/handle/123456789/27109, diakses pada 15 Desember 2017).

Sunu, P. 2001. Melindungi lingkungan dengan menerapkan ISO 14001. Jakarta: Gramedia Wardhana, Wisnu Arya. 2004. Dampak Pencemaran Lingkungan. Yogyakarta: C.V Andi Offset 